\title{
Bilişim Devrimi, Sibernetik İletişim ve Stratejik Halkla İlişkiler
}

\author{
Murat Sezgin ${ }^{a^{*}}$, Lütfiye Talaz \\ a Uşak Üniversitesi İletişim Fakültesi, Uşak. \\ bUşak Üniversitesi Kütüphane ve Dökümantasyon Daire Başkanlığı, Uşak
}

\begin{abstract}
$\ddot{O} z$
Teknolojinin gelişimi önü alınmaz bir hızla devam etmekte, her gün yeni teknolojilere ait yeni araç gereçler vitrinleri süslemektedir. Bu teknolojiler, hayatı yeniden yapılandırma ve kolaylaştırma açısından son derece bașarılıdırlar. Eskiden ütopik olarak görülen insana ait özelliklerin bir makinede olması, günümüzde normal karşılanan ve olması beklenen bir durumdur. $B u$ değişimlerin ortaya çıkardığ ăg teknolojileri, sanal alem, siber dünya ve siber kültürde hayatlarımızda yerlerini almıştır. Hayatımıza yön vermeye başlayan bu teknolojiler; bilimden sanata, kültürden tarihe kadar bütün disiplinleri doğrudan veya dolayl olarak etkilemeyi başarmıştır. Değişimi yakından takip etmek zorunda olan halkla ilişkiler alanı da, bu teknolojilerin nimetlerinden yararlanmaktadır. Halkla ilişkilerin siber çă̆da yaşadığı değgişim, yeni bir araştırma alanı olarak karşımıza çıkmaktadır. Bu çalışmanın araştırma konusu, sanal yaşam ve sanal dünya ile hayatımıza giren kavramlar, sibernetik iletişim ve sibernetik kültürün birbiriyle olan bă̆lantısı ve halkla ilişkilerin siber çă̆da ne konumda olduğudur. Bu çalışma ile siber çağın kavramlarının tanımları yapılacak, kavramların doğuşundan bahsedilecek ve birbiri arasındaki ilişki incelenecektir. Araştırma sonucunda, varılacak yargı ve araştırmanın yorumlanışı ile yeni çalışmalara kaynak oluşturulması hedeflenmektedir.
\end{abstract}

Anahtar kelimeler: Bilişim, sibernetik, stratejik halkla ilişkiler, sibernetik iletişim, sibernetik çă̆

\section{Informatics Revolution, Cybernetics Communication and Strategic Public Relations}

\begin{abstract}
Improvement of technology has been continuing with unstoppable speed. New gadgets belonging to new technologies has been decorating showcases day by day. These Technologies are tremendously successful. Machines' having human like properties, which was seen as utopic in old times, confronts us with a situation which is confronted as normal and is expected to occur. Web technologies which have been revealed via these changes, have sat in our lives in virtual world, cyber world, and cyber culture. These technologies which have started to give direction to our lives, have succeeded to effect whole disciplines directly or indirectly from science to art, from culture to history. Public relations field, which has to follow the change closely, has been benefiting from technology's blessings. The transformation of public relations in cyber age confronts us as a new research area. The notions which have entered to our live via virtual world and virtual live, the relation between cybernetic communication and cybernetic culture and in which position public relations stand in cyber age, are research field of this work. Definitions of notions of cyber age will be done with this work, and the birth of notions will be mentioned, and the relation between them will be looked at. As a result of research, it is targeted to compose source for new studies via the judgement which will be passed on and commenting of research.
\end{abstract}

Key words: Informatics, cybernetic, strategic public relations, cybernetic communication, cybernetic age. 


\section{GíRiş}

20. yüzyıl insanlık tarihine teknolojinin imkânlarından yararlanmayı armağan eden çağdır. Bu yüzyılda başlayan teknolojik gelişmeler, içinde bulunduğumuz yirmi birinci yüzyılda da devam etmektedir. Her yeni teknoloji beraberinde; yeni yaşam tarzları, yeni bilimsel yöntemler, yeni araştırma alanları, yeni kuramlar getirmektedir. Yeni olan her şey, yeni bir çağ açma konusunda yeni fikirler ortaya çıkarmaktadır.

Matbaanın icadı ile dünya, inanılmaz bir gelişim ve değişimin rüzgârına kendini bırakmıştır. Matbaanın bu etkiyi yaratacağı, bulan kişi tarafından belki de hayal bile edilmemiştir. Kullanıma başlanması ve bilimin yayılmasına etkisi görüldüğünde, bir icadın bir devri değiştirdiğinin kanıtı ortaya çıkmıştır. Aynı büyük değişimi, buharlı lokomotifin bulunması da sağlamıştır. Bu icat, sanayi devrimi diye adlandırdığımız ve toplum temellerini kökünden sarsan bir devir ortaya çıkarmıştır. $\mathrm{Bu}$ devrin ardından; ekonomik, ticari, kültürel, siyasal alanlardaki değişiklikler, günümüz dünyasının bugünkü şeklini almasında büyük rol oynamıştır. Bütün bunların ardından ortaya çıkan bilgisayar ve internet ise, diğer icatlar gibi toplumsal değişikliklere neden olmuştur. Bu icatlar da toplumsal hayatta köklü değişiklikler meydana getirmiştir.

Endüstri devrimine neden olan buhar makinesi gibi internet/bilgisayar da iletişimde devrim yaratmıştır. Bilgisayar/internet bireylerin birbirleriyle iletişim kurmasına ve bilgi edinmesini daha kolay hale getirmiştir. Hatta insanlar artık bilgiyi herhangi bir aracı kişi olmadan doğrudan kaynağından ve kendi durumlarına uygun şekilde alma seçeneklerini de göz önünde tutarak öğrenebilmektedir. Hızla küçük bir köy halini alan dünyada kendini ispatlamaya çalışan insan bilgisayar/internetle bilgiye ulaşmanın maliyetini en aza indirerek en uzak yerlere zaman sınırlaması ve eşik bekçisi olmadan ulaşabilmektedir.

Bilgisayar ve internet bilim adamlarına farklı ilhamlar vermiştir. Teknolojik alanda bir patlamaya sebep olan bu ilhamlar, hayatlarımızı hem kolaylaştırdı hem de içinden çıkılmaz sonuçlar doğurmuştur. Bilişim ve sibernetikte bu zamanlarda ortaya çıkan ve hayatımızı kolaylaştırmayı amaçlayan kavramlar olarak bu dönemde hayatımıza girmiştir. Bu kavramların tanımları, çalışmamızın başlıklarında yapılacak ve hayatımıza etkilerine bakılacaktır.

\section{Bilişim Devrimi ve Teknolojisi}

Bilişim kavramı, bilgisayar ve internet ile özdeşleşen bir kavramdır. İnternet ve bilgisayar, doğuşundan itibaren birbirleriyle paralel gelişme göstermişlerdir. Bu gelişmeler doğrultusunda da yalın teknolojiler olarak kalmamış, hayatın içerisine kendileriyle bağlantılı yeni kavramlar sokmuşlar, olan kavramlarının işleyiş şeklini değiştirmişlerdir. İnternet ve bilgisayarın gelişimi bilişim kavramının değişimine de sebep olmuştur. Bilişimin yaşamı değiştirmedeki rolü, bilişim devrimi olarak adlandırılan süreç incelendiğinde ortaya çıkmaktadır. Bu devrim, bilgisayarların ortaya çıkması ile farklı bir yapıya bürünmüştür. 
Mc Luhan insanlık tarihini teknolojiyi merkeze alarak üç döneme ayırır: Bunlardan birincisi 1500'lerden önceki dönem; kabile dönemidir. Bu dönemde yüzyüze iletişim söz konusudur. İkinci dönem; 1500-1900 lü yıllar arasındaki mekanik dönemdir. Bu dönem yazılı kültür ve iletişimin geliştiği dönemdir. Üçüncü dönem 1900'lerden sonraki dönem olan elektronik çağdır. Bu dönemde iletişim teknolojileri ortaya çıkmış ve iletişim eylemi bu teknolojiler üzerinden sürdürülmeye başlamıştır. $\mathrm{Bu}$ teknolojilere radyo, televizyon ve internet teknolojilerini örnek verebiliriz. (Güngör, 2013: s. 178) Mc Luhan'ın bahsettiği son dönemin içerisine bilişim çağı eklenmelidir.

"Modern bilişim tarihi yaklaşık 100 yıllık bir geçmişe sahiptir. Bu dönem içinde bilişim konusunda yapılan çalışmalar yazılım ve donanım temelli olmuştur. Hâlbuki özellikle birinci Dünya Savaşı sonrası ikinci Dünya Savaşı sırasında ve sonrasında insan makine etkileşimi yaklaşımı çerçevesinde bilişim çalışmaları başlamıştır. Bu konu önce insan hayvan ve insan arasındaki etkileşim çerçevesinde incelenmeye başlanmış daha sonra çalışmalar insan makina etkileşimine yönelmiştir. İnsan makine etkileşiminin temelinde de iletişim yatar. Bu nedenle bilişim konularının iletişim şemsiye kavramı altında incelenmesi çok önemlidir."(Çetinkaya, 2015: s.9)

Bilişim, bilgi ve iletişim kavramlarının teknolojiyle birleşmesiyle oluşmuş, telaffuz edildiğinde elektronik ya da sanal kavramlarını beraberinde getiren bir kavram olarak açıklanabilir.

Bilişim: İnsanoğlunun teknik, ekonomik ve sosyal alanlardaki iletişiminde kullandığı ve bilimin dayanağı olan bilginin, özellikle elektronik makineler vasıtasıyla, düzenli ve hızlı biçimde işlenmesi bilimidir (Köksal, 1981: 126)

Bilgi çağı olarak adlandırılan içinde yaşadığımız çağ, bilişim teknolojilerinin hızıyla doğrudan ilişkilidir. Bilişim teknolojilerinin başında bilgisayar gelir.

Bilgisayar, sadece toplumsal aracın(medium), herkesin her birine, her birinin de aynı olana katılmasını düzenleyen bu en küçük ortak kültürel sinyaller sisteminin teknik olarak somutlaşmasıdır (Baudrillard,2015: 129). Dolayısıyla bilgisayar-insan etkileşiminin temelinde de iletişim yatar.

1937'de ilk bilgisayar olarak tarihe geçen IBM'in yaptığı bilgisayardan sonra II. Dünya Savaşı sırasında yapılan ENIAC ilk elektronik bilgisayar olarak kullanılmaya başlandı. 1981 yılında IBM in piyasaya sürdügü PC'lerden sonra bilgisayar teknolojileri hızı yakalanamaz hale geldi. Günümüzde her yeni güne yeni bilgisayar teknolojisiyle uyaniyoruz (Bostancı Ege, 2004).

1950'lerde bilgisayarların üretilip satılmaya başlanması ile hızlanan bilgisayar çağı ve internet, dünyayı küresel bir köy haline getirdi. Bu durum, dünya üzerindeki bilgi teknolojileri ağıyla oluşturuldu. Bu ağlara soyut otoyollar olarak adlandıranlar oldu. Kablolarla örülmüş bu ağlar saniyeler içerisinde dünyanın bir ucundan diğer ucuna bilgi aktarma, iletişim kurma ve hatta günlük işlerimizi bile bu ağlar üzerinden yürütmemize imkân verdi. Teknolojik imkânların bu denli arttığı günümüzde 
bilgisayarlardan tabletlere, cep telefonlarına kadar, birinin özelliği diğerinde bulunan teknolojik cihazlar gelişti. Bilgisayarlı ağ toplumundan mobil ağ toplumuna hızlı şekilde geçildi. Bu sayede ağlar üzerinden gerçekleştirdiğimiz işler, teknolojik araçlara bağımlı hale geldi. Bir banka hesabından başka bir banka hesabına para göndermek için bankaya gitmemize gerek kalmadı. İnternete bağlanabilen bir cihazımızın olması bu işi oturduğumuz yerden yapmamıza fırsat verdi. Bu noktada, elimizde internete bağlanabilen bir cihaz olması bu işlem için gerekli olan iki bağımlılığı ortaya koyuyor. Bunlardan birisi internete erişimin olması, diğeri internete bağlanan bir cihaza sahip olunmasıdır. Dolayısıyla bilişim çağı ve teknolojileri internet ve teknolojilerine bağımlı olan süreçlerdir diyebiliriz.

Teknolojik gelişmelerin savunucuları teknolojik gelişmelerin insanın doğal güçlere karşı köleliğini sonlandıracağını ve onları özgürleştireceğini savunur. Heidegger ise insanın her teknolojik üretimi yöneten gücün kölesi olacağını ileri sürer. Teknolojik sistemlerin insanın kontrolü altında olmaması sibernetik sistemlerde kolaylıkla anlaşılabilir der. Teknolojinin insanları yeryüzünden köklerinden kopardığından bahsedilir. (Zimmerman, 2011).

Bilişim devrimi ve teknolojisinin hayatımızın her alanına etkisi altında bıraktığı karşı konulmaz bir gerçektir. Hangi alanda nasıl etkiler bıraktığını incelemek için ayrı ayrı başlıklar altında ele alınmalıdır. Medyayı, kültürü, ekonomiyi, siyaseti, sanatı, eğitimi etkisi altına alan ve hayatın her alanına sızan bilişim teknolojileri insana farklı bir yaşam biçimi de sunmuştur. Bunlardan bir tanesi de sanal dünyada yaşamdır. Sanal dünya, soyut bir dünya olmasına rağmen; daha mutlu yaşatma, daha çok imkan sunma ve gerçek dünyadan uzaklaşma vaatlerini, dahil olan herkese sunmayı cömertçe yapar. Bu imkanların soyutluğunu unutup gerçek dünyanın somutluğundan kaçan insan kendisini bu soyutluğa dahil eder.

Bilişim devrimine giden yolda birçok gelişme yaşanmıştır. Bu gelişmelerden ön plana çıkanları ise bilgisayar ve internet dünyasında yaşanan süreçler olmuştur. Ancak tüm bu gelişmelerin arkasında özellikle sibernetik ve yapay zeka alanında yapılan araştırmalar ve ortaya çıkan buluşlar, bilişim devrimi yaratan gizli kahramanlardır (Küçükvardar, 2015). Bilişim devriminin gizli kahramanları bir sonraki bölümde incelenmiştir.

\section{Sibernetik}

Sibernetik, Matematikçi Norbert Wiener tarafından ortaya çıkarılmış bir kavramdır. Mutlu(2004: 253) kavramın tanımını şu şekilde yapmıştır: Gerek mekanik gerekse insana yönelik bilgi sistemlerinde iletişimi denetleyip yönetme bilimi: güdümbilim.

Sibernetik, insanlar ve hayvanlar arasında iletişim ve kontrol bilimi olarak önerilmiştir. Kelime anlamı yönetimdir. Weiner, fizik, elektronik, bilgisayar, felsefe, matematik, psikoloji, psikiyatri, sosyoloji, fizyoloji gibi farklı bilimler temelinde iletişim ve kontrol için ortak olan problemlerin öğrenilmesi gerektiğine değinmiştir. Bu alanların ortak özellikleri olduğuna inanan Weiner bütün bunları tek bir kavram olan 
sibernetik adı altında birleştirdi. Sibernetiğin en önemli özelliği, canlı ve cansız sistemler arasındaki farkın bilerek önemsenmemesidir. Kısacası sibernetiği canlılar ile makineler arasındaki ilişkilerin kontrolünü araştıran bilim olarak tanımlayabiliriz (Nabiyev, 2010: 50-51)

Wiener, sibernetik kavramı için "insanın makineyle etkileşimi esnasında onun üzerindeki hâkimiyeti" benzetmesini yapmıştır. Wiener' in diğer tespiti de tüm insanmakine etkileşimlerinde ya da ara yüz tasarımlarında insanlar arasındaki iletişimin insan-makine ve makine-makine arasındaki etkileşimler için model olarak alınmasıydı (Küçükvardar, 2015). Dolayısıyla sibernetik kavramının temeline ilham kaynağı olan şeyin, insanlar arasındaki iletişim olduğunu diyebiliriz.

Sibernetiğin, "bilim dalları arası kontrol bilimi" (Erkal, 2004: 262) olarak yapılan bir tanımı da vardır. Sibernetikte, sabit bir geri beslemeyi değiştirecek herhangi bir faktör sabit işleyişte değişikliğe neden olur fikri ön plandadır. Bu fikir bize sibernetiğin, çevreden etkilenen canlı bir yönetim ve kontrol bilimi olduğunu gösterir. Sibernetik biliminde stratejinin önemi burada ortaya çıkar. Çünkü sabit bir geribeslem istiyorsak sabit bir stratejik yolumuz olmalıdır.

Sibernetik aralarında bilgi alışverişi, ayarlama, kontrol ve yeniden mekanizmaların kurulduğu sistemleri inceleyen bir disiplindir. Bazı bilim adamları sibernetiği kendi kendini idare etme bilimi olarak ifade ederler. Sibernetik canlılarda kendi kendini düzenleyen makineler arasındaki çalışma benzerliklerini araştırır. bu bakımdan "organize varlıkların davranış bilimi" şeklinde de düşünülebilir(Kaban, 1994).

Heidegger, e felsefenin yerini ne almıştır sorusu sorulduğunda, sibernetik cevabını vermiştir. Sibernetik tarzda takdim edilen bir dünyada otomatik makineler ile canlılar arasındaki farklar ortadan kalkar. Homojen bir enformasyon süreci dünyayı nötrleştirir. Sibernetik dünya projesi; yöntemin bilim karşısındaki zaferi demektir. Sibernetik canlı cansız dünya arasındaki kontrol edilebilirliği mümkün kılar.(Zimmerman, 2011: 346)

Sibernetik sistem yaklaşımının sosyal sistemlere uygulanabilirliği, mekanistik sistemlere göre daha üstündür. Mekanik sistemlerde feedback olmayışı sibernetik yaklaşım da böyle bir imkan sunulması onun sosyal sistemlere uyarlanmasını sağlamıştır (Tekeli, 2011: s.181)

Genel itibariyle sibernetik; insan-makine arasında etkileşim kuran, bütün bilim dalları için ortak olan iletişim-kontrol süreçlerini içine alan, geribeslem için pratikler yaratan mekanik sistem olarak tanımlanabilir.

Sibernetik bilimi, insan hayatına çok farklı şekillerde girmiştir. Sibernetik sayesinde yeni kavramlar ve yeni türler ortaya çıkmıştır. Bu türlerden birisi siborglardır. Siborg kavramı ile adı özdeşleşen bilim insanı Donna Haraway'dir. Ona göre: Siborg: makine ile organizmanın teorik bir zeminde ifade edilen ve fabrikasyon misali uydurulmuş birer melez olduğu durumdur. Haraway(2006), günümüzde doğal ile yapıntı olan, zihin ile beden, kendi kendini geliştiren şey ile diştan tasarlanan şey 
arasındaki farklılığı ve organizmalar ile makineler açısından geçerli olabilecek başka bir sürü ayrımın belirsiz bir noktaya geldiğinden bahseder (Haraway, 2006: 10). Bunun nedeni de sibernetiğin hayatlarımıza uygulanmasıdır.

Siborglar gibi sibernetik ile hayatımıza, "siber" ön adlı pek çok kavram girmiştir. Sibernetik çağ, sibernetik teknoloji, sibernetik kültür, siberuzay, sibernetik iletişim, sanal alem, sanal gerçeklik bunlardan bazılarıdır. Bu kavramların tanımları alt başlıklarda incelenecektir.

\subsection{Sibernetik Çağ ve Sibernetik Teknoloji}

Dünya, bugüne kadar yaşadığı değişimlerin büyüklüğüne ve bu değişimlerin hayat tarzlarını değiştirişine göre çağdan çağa atlamıştır. Eski dünyaya göre yeni dünya da değişimler hem daha çok hem daha sık yaşanmaktadır. Bu yüzden eskiden yüzyıllarla bölünmüş çağlar, günümüzde çok kısa sürelerle bölünmektedir. Dünkü tarihe modern çağ derken, bugünkü tarihe postmodern çağ demek son derece hızlı gerçekleşebilmektedir. Benzer şekilde düne sanayi çağı derken, bugüne enformasyon çağı demek son derece kolaydır. Çağlar, birbirinden tam anlamıyla ayrılmış süreçler olmamakla birlikte, birbirinin de tamamen aynısı olamazlar. Çoğunlukla iç içe geçmişlerdir. Çalışmamızda ayrı başlıklarda ele aldığımız bilişim çağı ve sibernetik çağ da aynı şekilde birbirinden ayrılamayacak derecede iç içe geçmiş çağlardır. Bu çağların ayrı adlandırılmasının nedeni, bazı durumlarda yöntemlerinin değişmesinden kaynaklanmaktadır.

Sibernetik çağ; içinde insan-makine etkileşimini barındıran çă̆ olarak tanımlanabilir. Bu etkileşime örnek olarak insan işlerini yapabilen insan gibi davranan bir robot verilebilir. Başka bir örnek olarak insan organı olmadığı halde organı çalıştırabilen bir kalp pilinden bahsedilebilir. Bu örnekler bize insan makine etkileşimindeki kontrol ve iletişimi gösterecektir. Sibernetiğin özelliği olan bu etkileşim sibernetik çağın merkezindedir.

Sibernetik çağın kendine özgü teknolojik anlamda araç gereçleri vardır. Bu araç gereçler canlı ile cansız arasındaki farkları ortadan kaldıracak türde araç gereçlerdir. Sibernetik çağın bir başka özelliği de insanlara yeni bir yaşam alanı olan sanal alemin kapılarını açmasıdır.

Gelenekler ve görenekler; sosyal kabul ve ihtiyaçlarla bağlantılı olduğuna göre, sosyal ihtiyaçlar da siber çağda ortadan çok büyük ölçüde kalkacak veya de değişim geçirecek ve sanal bir dünyanın başka ihtiyaçları ortaya çıkacaktır (Türkeş Günay, 2013). Sanal dünyadaki ihtiyaçlar hem doğal hem yapay ihtiyaçlardır. İletişim hem doğal dünyanın hem sanal dünyanın vazgeçilmezidir. İletişim ihtiyacı doğal bir ihtiyaçken sanal alemde iletişim kurmayı gereksinim olarak görmek yapay bir ihtiyaçtır.

Sonuç olarak; sanal dünya ihtiyaçlarımızı, yaşayışımızı ve hatta hem ruhsal hem fiziksel sağlığımızı etkileyecek kadar güçlü bir mecraadır. Hayatı sibernetik çağda farklılaşmış insanın, ihtiyaçlarının değişmesi, kültürü de doğal olarak etkileyecektir. Sibernetiğin kültür üzerindeki etkisi sonraki başlıkta ele alınmaktadır. 


\subsection{Sibernetik Kültür}

Toplumlar yaşadığı çevreden ayrı düşünülemez. Kültürde bu yaşayan organizmaların yaşayış biçimlerini temsil eden bir değerler bütünüdür. Kültür çevresinden çok kolay etkilenen bir değerler bütünüdür. Dolayısıyla toplumda meydana gelen herhangi bir değişim doğrudan kültürü etkiler. Bazı durumlarda bu değişimlerin boyutları, o güne kadar gelmiş kültür sisteminin temellerini altüst edebilir. Bugüne kadar toplumların yaşadığı bütün değişimlerin izleri kültür üzerinde görülür. Siber teknolojilerde bu izlerin oluşmasına katkı yapan teknolojilerdir. Her yeni buluş gibi, siber teknolojilerde toplumu ve kültürü bir sosyalizasyon sürecinin içine sokmaktadır.

Yaşanan teknolojik devrim ve internetin yaygın kullanımı ile birlikte kültürel alanda büyük değişiklikler meydana gelmiştir. Bilgisayara dayalı kültürel dünyayı sibernetik kültür temsil eder (Bostancı Ege, 2004).Teknolojik gelişmeler ile kültür arasında doğrudan bir ilişki vardır. Teknoloji kültürü, kültür teknolojiyi etkiler.

Innis, teknolojinin toplumsal örgütlenmeye ve kültüre etki ettiğini, bunlarl; değiştirdiği ve biçimlendirdiğini söyler. (Erdoğan\&Alemdar, 2010: 147)“Innes'e göre telgraf dilde daralmayı dayattı insanlara. Gazeteler, dergiler, çok satan kitaplar, edebiyat, aralarında çok az iletişim olan okur kesimlerini yarattı" (Güngör, 2013: s.172)

Tanımlardan anlaşılacağı gibi sibernetik çağ da sibernetik bir kültür oluşması için siber kültürel bir ortam oluşmuştur. Tarihteki diğer örnekler gibi, yeni bir gelişme kültürü kökünden etkilemiştir.

\subsection{Sibernetik İletişim}

İletişim; mesajlarla karşılıklı etkileşim kurma işidir. İletişimin klasik tanımlarından bir tanesi; bir mesajın gönderilmesini gerçekleştiren gönderen, bu mesajın gönderildiği kanal ve bu mesajı açımlayan alıcıdan meydana gelen mesaj gönderim ve alım işidir, şeklindedir.

Günümüzde iletişim etkinliğinin gerçekleşmesi, farklı kanallar yoluyla olmaktadır. Teknoloji, bu kanalları farklılaştıran unsurlardan birisidir. Teknolojiyle şekillenen bir dünyada, teknolojiden etkilenmeyen iletişim düşünülemez. Sibernetik dünyanın da faktörü olan teknoloji ile matematiksel iletişim denilen iletişim sistemi ortaya çıkmıştır.

Matematiksel iletişimden kasıt: Matematiksel iletişim kuramı ile enformasyon ölçülebilirlik kazanmasıdır (Er, [Tarihsiz]).

Sibernetik çağda sadece matematiksel anlamda iletişim değişmedi. Bunun yanı sıra iletişim mecralarında sunulan şeyler de değişti. Sinema, radyo, televizyon, bilgisayar, internet, yeni ve eski medya ve iletişim mecraları olarak günümüzde halen etkilerini fazlasıyla sürdürmektedir. Bu kadar etkili mecraların kontrolü son derece önemlidir. Sibernetik çă̆ ile birlikte bu alanlardaki iletişimin kontrolü çeşitli teknolojilerden yararlanılarak sağlanmaktadır. 
Bir tanımda sibernetik: "Makine ve hayvanlarda bir iletişim bilimidir"olarak tanımlanmıştır (Hallaç\&Öz, 2014). Bu tanım sınırlı bir tanım olarak kabul edilebilir. Bunun sebebi sibernetiğin sadece makine ve hayvanlarda iletişim bilimi olmamasıdır. Sibernetik, canlı ve cansız arasındaki iletişimide işaret eder.

Norbert Wiener'e göre "vâr olmak, tümüyle enformasyon yoluyla vârolmakla mümkündür" ve bu nedenle "iletişim içinde vâr olmak" şeklinde düşülmediği sürece insanı anlamak mümkün değildir demiştir (Küçükvardar, 2015). Bu yüzden sibernetiğin temel mottosu, canlı ve cansız varlıkları iletişim içinde var etmektir.

Sonuç olarak; zaten iletişim sistemi üzerine kurulmuş olan sibernetik çağın içerisinde sibernetik iletişim kavramını incelemek, sibernetik çağa ayrıntılarıyla vâkıf olmamamızı sağlar.

Sibernetik çağda iletişimsel eylemlerin gerçekleştiği diğer bir alan siberuzaydır. Siberuzay sonraki başlıkta ele alınmıştır.

\subsection{Siberuzay}

Bilgisayarlar ile hayatımıza giren kavramlardan bir tanesi de siberuzaydır. Siberuzay; bilgisayarların oluşturduğu, sanal etkileşimlerle dolu, bildiğimiz uzay gibi bilinmezleri fazla, sınırları bilinmeyen, soyut bir ortamdır.

Siberuzay kavramı ilk olarak William Gibson tarafından kullanılmıştır. Siberuzay bilgisayarların iletişim amacıyla kullanılmasıyla doğan yeni uzayları ifade eder. Siber uzay yapay bir ortamdır. Siber uzay sanal yaşam alanı olarak adlandırılabilir. Siberuzay, bir bilgisayarın başına oturduğumuzda gerçek yaşam kimliklerimizi, bedenimizi ardımızda bırakma deneyimini bizlere sunar (Bostancı Ege, 2004).

Siberuzay aynı sanal gerçeklikte olduğu gibi iki parçadan oluşmaktadır. Bunlardan ilki fiziksel bileşenlerdir. Bilgisayar sistemleri, elektronik makineler gibi aletler fiziksel bileşenleri oluşturur (Küçükvardar, 2015)

Siberuzay, olmak istenilen şekilde bir profil oluşturmak açısından bireylere imkan sağlar. Farklı kimliklere bürünen insan kendisini ifade ederken bu kimlikler altında ifade etmenin hazzını siberuzayda yaşar. Dolayısıyla siberuzaya dünyanın alternatifi demekte bir sakınca yoktur.

Sibernetik çağ ile hayatımıza giren siberuzay kavramından doğan diğer bir kavram da siberuzamdır. İletişimciler arasında çok fazla kullanılan bu kavram şu şekilde tanımlanmıştır: Siberuzam; Dünyanın bilgisayar ve iletişim hatlarıyla yaratılan ve beslenen paralel bir evrenidir (Mutlu, 2004: 253).

Görüldüğü üzere siberuzay ve siberuzam birbirine çok yakın anlamlı iki kavramdır. İkisi de soyut ve dünyaya alternatif bir evrenden bahseder.

Siberuzam veya siberuzayın içinde yaşanan deneyimlere, eylemlere sanal adı verilir. Sanal kavramını sanal dünya ve sanal gerçeklik başlıklarında incelemekte yarar vardir. 


\subsubsection{Sanal Dünya ve Sanal Gerçeklik}

Sanal, zihinde düşünce ile var olan ama gerçekte somut olarak o anda ve mekanda olmayan şey olarak tanımlanabilir.

Sanal; Reel dünyadaki gerçeklik anlamıyla hakiki bir fiziksel gerçekliği olmayan ve ancak siberuzayda bilgisayar teknolojisinin sunduğu olanaklarda dijital olarak var olabilen eylem, nesne varlık ve yerleri ifade etmek için kullanılan bir terimdir (Bostancı Ege, 2004). Sanal dünyanın ham maddesi internettir.

Baudrillard'ın kurduğu simülasyon kuramında insanlar kendi gerçekliklerinden uzaklaşıp hiper gerçeklik dünyasına çekilirler. Bu dünya, gerçekliğin taklidi de değildir, yeniden üretimi de değildir. Burası gerçek dünya kurallarından bağımsız bir dünyadır. Bu dünya sanal bir dünyadır ve bu dünyada mesafeler belirsizdir, gerçek ile düş arasındaki sınırlar yoktur, her şeyin sanal olarak yaşanması söz konudur. (Güngör, 2013: s. 191)

Sanal dünya ile benim soyut gerçek dediğim, sanal gerçeklik ortaya çıkmıştır. Sanal gerçeklik insanlara gerçek-“miş" gibi imkanını sağlayan teknolojilerden oluşur.

Sanal gerçek; bilgisayar ve internet gibi yeni teknolojilerle yaratılan çevreye verilen isimdir. Sanal gerçekte gerçeğin aynısı taklit edilir. Gerçek olmayan ama gerçek olarak deneyimlenen gerçektir. (Erdoğan\&Alemdar, 2010: 322)

Sanal gerçeklik, simülasyon geleneğini devam ettirmektedir. Fakat aralarında önemli bir fark bulunmaktadır. Simülasyon, gerçek fiziksel mekâna bağll, onun uzantısı olan yapay bir ortam oluşturmaktadır. Halbuki sanal gerçeklikte sunulan yaşam gerçek olandan bütünüyle kopuktur (Küçükvardar, 2015).

Sonuç olarak; siber ve sibernetik ön başlıklı bütün kavramlar, insan hayatını kökten değiştiren bilgisayar ve bilişim teknolojileriyle sanal kavramını da hayatımıza dahil etmiştir. Teknolojiler ilerledikçe yeni kavramlar ortaya çıkacak ve hayatımızı etkileyecektir.

\section{Stratejik Halkla İlişkiler Bağlamında Bilişim Çağı ve Sibernetik İletişim}

Halkla ilişkiler tanımları; halkla ilişkilerin, bir yönetim aşaması, iletişim kurma yöntemi ve ilişki yönetimi oluşu üzerinde yapılır. Genel olarak halkla ilişkiler üzerine yapılan tanımlar toplandığında halkla ilişkilerin genel tanımı şu şekilde yapılmıştır: İletişim sürecinin iki yönlü doğasını vurgulayan halkla ilişkiler karşılıklı iyi niyet kurulmasını sürdürülmesini destekleyen, kurum adına bilgiyi toplayıp, yorumlayıp analiz eden, kurumun amaçlarını belirlemesine ve gerçekleştirmesinde yardımcı olan, tanıma ve tanıtma misyonunu üstlenmiş bir süreçtir (Kalender\&Fidan,2011).

Organizasyonlar, misyon ve vizyonunu gerçekleştirmek üzere izleyeceği yolu belli plan ve program çerçevesinde gerçekleştirmek zorundadır. Yapılacak plan ve programların içerisinde, hangi işin ne kadar sürede, ne kadar kişiyle yapılacağı, çevre koşulları, organizasyon koşulları gibi her aşamanın hesaplanması gerekir. Gidilecek yolun hesaplanması ancak strateji ile olur. Organizasyonun her biriminin gidilecek 
yoldaki görevini bilmesi stratejinin benimsenmesine bağlıdır. Organizasyonların yolunu belirleyen stratejinin tanımı şu şekilde yapılmıştır:

Strateji, kurum ve çevresi arasındaki ilişkilerin analiz edilebilmesini sağlayan, kurumlara faaliyetleri sırasında amaçlarını ve ulaşacakları hedefleri gösteren bu noktada kurumlara yön çizen, bu doğrultuda uygulayacakları faaliyetleri ve bu faaliyetleri uygularken kullanacakları kaynakları belirten ilerisi için bugünden alınmış kararlardır (Göksel, 2013: 8).

Halkla ilişkiler anlamında strateji; halkla ilişkiler faaliyetlerinin belirli bir plana göre uygulanması, hedeflenen halkla ilişkiler amacına ulaşılması için gerekli basamakların önceden planlanmasıdır.

Stratejik halkla ilişkiler sürecinde örgüt ve hedef kitle için pek çok faktör analiz edilir. Stratejik faaliyetler bir olayın öncesi ve sonrası ile tüm olasılıklarının hesaplanmasını gerektirir. Bu hesaplamalar içerisinde şu faktörleri barındırmalıdır:

- $\quad$ Hedef kitle analizi

- $\quad$ İç ve diş çevre analizi

$\mathrm{Bu}$ analizler kendi içerisinde müşteriler, tedarikçiler, çalışanlar, rakipler, hissedarlar, teknoloji, doğal çevre, sosyo-kültürel çevre, siyasi çevre, ekonomik çevre vs. şeklinde detaylandırılabilir(Göksel, 2013).

Stratejik halkla ilişkiler ile bilişim ve sibernetiği ilişkilendirme aşamasında bakacağımız alanlar; stratejik plan ve dış çevre faktörlerinden; teknoloji ve kültürel çevre olacak.

Teknolojik değişimler işletmenin amaçlarını gerçekleştirmesini iyileştirebilecek büyük fırsatlar sunduğu gibi, işletmenin mevcudiyetini de tehlikeye sokabilir (Göksel, 2013:s.68). Bu bakımdan bir işletmenin teknolojik ilerlemeleri çok iyi takip etmesi ve kullanması gerekir. Bunu mümkün kılabilmek için, işletmenin bir stratejik planının olması gerekir.

Kültürel çevre, insanların yaşam tarzları, tüketim alışkanlıkları, boş zaman değerlendirme alışkanlıkları, gelenek, görenek, tutum, din, değerler gibi pek çok faktörden oluşur (Göksel, 2013:70). Günümüz dünyasında kültürel dünyayı değiştiren en önemli faktörler; bilişim, teknoloji ve küresel dünyadır. Halkla ilişkiler faaliyetleri gerçekleştirilirken kültürel çevrenin analizinde bu ayrıntılar göz önüne alınmalıdır. Bunlarda stratejik bir plan ile mümkün olur.

İnternetin bireylerin gündelik yaşamlarında giderek daha çok yer almasıyla online olarak veri toplamak halkla ilişkiler programları açısından bir seçenek haline gelmiştir. Online olarak yapılan araştırmalar: memnuniyet araştırmaları, tutum davranış araştırmaları, konsept testleri, reklam ön testleri, web site testleri, ürün testleri, kamuoyu araştırmaları olarak örneklendirilebilir (Güzeloğlu, 2012: 124-125). Dolayısıyla bilişim halkla ilişkiler faaliyetlerinin de merkezine oturmuştur.

Stratejik halkla ilişkilerde diğer bir önemli unsur kişilerarası iletişimdir. Teknolojinin nimetlerinden yararlanarak kişilerarası iletişim aşamasını tamamlamak 
hem zaman açısından, hem mekan açısından avantaj sağlamaktadır. Telekonferanslar, online eğitimler, karşılıklı mailleşmeler siberuzaysal mecrada yapılan halkla ilişkiler faaliyetleridir. Dolayısıyla stratejik planını iyi yapmış bir organizasyon olmak dış ve iç çevre faktörlerini iyi izlemeyi ve onu şirkete uyarlamayı gerektirmektedir. Bilişim ve siber çağ olarak adlandırılan günümüz çağlarında, teknolojiden uzak duracağım görüşünü benimseyen hiçbir örgütün ömrü uzun vadeli olamaz. Halkla ilişkiler alanı, örgüte öncülük edip yön gösterme işini bu aşamada gerçekleştirmeli ve çağın gereklerini organizasyona adapte etmelidir. Kisacası ona rehberlik etmelidir. Bu da halkla ilişkilerin değişimi takip edip onun organizasyona uyarlamasındaki öncü rolünü gözler önüne serer.

Halkla ilişkiler alanında internetten yararlanma biçimleri arasında web siteleri, elektronik posta, intranet, extranet, online veri tabanları, blog, network, tartışma grupları ve chat yer almaktadır (Kalender\&Fidan, 2011:375). Bu faaliyetler siberuzayda sanal olarak gerçekleştirilen faaliyetlerdir.

Halkla ilişkilerin de bir sistem modeli olduğunu savunanların sayısı oldukça fazladır. Sibernetiğin de mekaniksel bir sistem olduğu düşünülürse, bilişim teknolojileriyle desteklenmiş sibernetik sistemleri içerisine katmış stratejik bir sistem, halkla ilişkiler için son derece önemli hale gelmektedir.

Halkla ilişkilerin öznesi bireydir ve birey bilişim çağında farklı bir varlığa bürünmüştür. Bu farklılık bireylerin sanallaşmasıdır. Siberuzay da dolaşan bireylerin varlık ya da yokluğu soru işaretlerini beraberinde getirir. Sonuç olarak; halkla ilişkiler onca değişim içerisinde yerinde saymaya devam eden bir alan olarak varlığını sürdüremezdi. Dolayısıyla dünyanın her yerini sanallık sarmışken, halkla ilişkilerinde özne konumuna sanal bireyleri de dahil etmesinin zamanı çoktan gelmiştir.

\section{SONUÇ}

$\mathrm{Bu}$ araştırma sonucunda, bilgisayarların ortaya çıkmasıyla birlikte, yeni bir sistem olarak ortaya çıkan sibernetiğin doğuşu ve etkilediği alanlar ortaya çıkarılmaya çalışıldı. Bu bağlamda, sibernetik çağ ve teknoloji, sibernetik kültür, sibernetik iletişim, sanal dünya ve sanal gerçeklik kavramları tanıtıldı. Bir yönetim süreci olan halkla ilişkilerin stratejik planlanması ile bu kavramlar arasında ilişki kurulmaya çalışıldı.

Weiner'in kanıtlamaya çalıştığı şeyin aslında bilinen fakat dikkatlerden kaçan bir şey olduğu bu çalışma sonucunda ortaya çıkmıştır. Bu bilinen şey; Weiner'in savunduğu bütün alanların birbiriyle ilişkisi olduğu gerçeğidir. Hepimiz biliyoruz ki bu dünyada birbirinden bağımsız yaşayan hiçbir şey yok. Buna canlı cansız bütün varlıkları dâhil edebiliriz. Bu varlıkların da hepsinin birbiriyle doğrudan veya dolaylı şekilde ilişkisi var. Canlı cansız bütün varlıkları inceleyen bilim dallarıyla, soyut ortamları inceleyen bilim dallarının da ilişkisi de bize bu gerçeğin yadsınamayacağını gösterir. Dolayısıyla aslında matematiksel bir mantık üzerine kurulan sibernetiğin halkla ilişkilerle ilişkili olabileceği bizi çok şaşırtan bir durum olmamalıdır. Sibernetik tanımında yer alan, "ilişkiler sistemi" ifadesi halkla ilişkilerle sibernetiğin ortak paydasıdır. Birisi hedef kitle, organizasyon işleyişi arasındaki ilişkinin kontrolünü 
ifade ederken, diğeri bütün alanların birbiriyle ilişkisini ve kontrolünü ifade etmektedir.

Küresel dünyada geniş kitlelere, daha hızlı ve daha etkili biçimde erişebilme imkânı sağlayan internet halkla ilişkilerin vazgeçilmez uygulama aracı olmuştur. Yeni iletişim teknolojilerinin halkla ilişkiler uygulamalarını nasıl ve ne amaçla değiştirebileceği sorusu henüz yanıtlanmış değildir. Peltekoğlu'nun (2012:313) söylediği gibi "Bilgiye erişmek değil, onu kullanabilmek önem kazanmaya başlamıştır." hedef kitlelere salt tek yönlü bir ileti akışını yerine getirmek değil, hedef kitlelerle sağlanacak ileti alış verişinin de etkin şekilde değerlendirilmesinin iyi bir halkla ilişkiler uygulaması için gerekli olduğu dikkate alınmalıdır

Başka bir yönünden halkla ilişkiler ve sibernetik arasındaki ilişki için şunlar söylenebilir: Halkla ilişkilerin başka alanlarla olan ilişkisinden de bahsetmek gerekir. Halkla ilişkilerin hangi bilim dallarıyla ilişkisi vardır sorusuna bütün bilim dallarını sayarak cevap verebiliriz. Çünkü halkla ilişkiler toplumun nabzının attığ1 yerdir. Toplumun ihtiyaçları için geliştirilen bütün bilim dalları da halkla ilişkilerle ilişkilidir. Dolayısıyla Weiner'in sibernetik sisteminin tanımını; kontrol bilimi, yönetim bilimi, organize varlıkların davranış bilimi, yönetim sistemi gibi kavramlarla yaparsak; halkla ilişkilerin tanımları arasında da mutlaka bu kavramlara erişiriz. Sonuç olarak diyebiliriz ki, sibernetik sistemi halkla ilişkilerle doğrudan ilişkilidir. Sibernetik çağa, sanallığın bilim dallarına küresel etkisinin yansıması denilebilir. Eğer bir yerde küresellikten bahsediliyorsa, orada halkla ilişkiler ilk başvurulacak alandır.

Parça içerisinde bahsedilen felsefenin yerini sibernetiğin aldığı iddaası sibernetiğin bütün bilim dallarını içerisine katmasından kaynaklanmaktadır. Eski çağlarda felsefenin geniş açısıyla açılamaya çalıştığı ilişkiler, günümüzde daha matematiksel görünen başka alanlarla yapılmaktadır. Weiner'de bunun için yeni bir sistem olan, bütün alanların birbiriyle olan ilişkisini ortaya çıkarmak üzere geniş açılı bir sistem olan sibernetik sistemi kurmuştur.

Sonuç olarak, halkla ilişkiler stratejik bir bilim dalıdır. Sibernetikte stratejik bir bilimdir. Halkla ilişkiler çağı takip etmeli ona göre yol haritaları belirlemelidir. Halkla ilişkiler alanında, bilişim, sanal, siber gibi günümüz dünyasının yeni terimlerine yer verilmeli ve bunların nimetlerinden yararlanılmalıdır. Stratejik halkla ilişkilerin görevi de budur.

\section{KAYNAKÇA}

Baudrillard, J. (2015). Tüketim Toplumu(7. Bsk). İstanbul: Ayrıntı.

Bostancı Ege, G. (2004).Siber Kültür, Bilgisayarların Sosyolojik Etkileri ve Siberuzayda Sosyal İlişkiler. (Yayımlanmamış Doktora Tezi) Ege Üniversitesi. İzmir.

Çetinkaya, A.\& Kırık, A. M.\& Şahin, Ö. E.(ed.) (2015). Bilişim ve...İstanbul: Hiperlink

Er, G. E. (2009). Siberkültürde Bedenin Görsel Sunumu: Serial Experiments Lain Adlı Anime Üzerine Bir Çözümleme. İstanbul Üniversitesi İletişim Fakültesi Dergisi. Sayı 36, ss.71-91.

Erdoğan, İ. \& Alemdar, K. (2010). Öteki Kuram. Ankara: ERK. 
Erkal, S. N.(ed)(2004). Alternatif Düşünceler Sözlü̆̆̈̈. (2. bsk.) İstanbul: İnsan.

Göksel, A. B. (2013). Stratejik Halkla Illişkiler Yönetimi. (2. bsk.) Ankara: Nobel.

Güngör, N. (2013). İletişim: Kuramlar ve Yaklaşımlar. (2. bsk.) Ankara: Siyasal.

Güzeloğlu, E. (2012). Halkla İlişkilerde Araştırma Uygulamaları ve Yeni Medya Araştırma Pratikleri. Göztaş, A. \& Topsümer, F. (ed.) Stratejik Halkla İlişkiler Yönetimi. Ankara: Seçkin. ss. (109-142).

Hallaç, S. \& Öz, F. (2014). Aile Kavramına Kuramsal Bir Bakış. Psikiyatride Güncel Yaklaşımlar. 6(2):142-153.

Haraway, D. (2006). Siborg Manifestosu: Geç Yirminci Yüzyılda Bilim, Teknoloji ve SosyalistFeminizm. İstanbul: Agora.

Kaban, Z. Y. (1994). Genel Sistem Teorisi ve Sibernetik. Marmara İletişim Dergisi. Sayı:8. Ss. 219226.

Kalender, A. \& Fidan, M. (2011). Halkla İlişkiler. (3. bsk.) Konya: Tablet.

Köksal, A. (1981). Bilişim Terimleri Sözlüğü. Ankara: TDK.

Küçükvardar, M. (2015). Bilişim Devrimi: Reel Gerçekliğin Sanal Gerçekliğe Dönüşümü. (Yayımlanmamış Yüksek Lisans Tezi) Marmara Üniversitesi Sosyal Bilimler Enstitüsü. İstanbul.

Mutlu, E. (2004). İletişim Sözlüğü̈. (4. bsk.) Ankara: Bilim ve Sanat.

Nabiyev, V. V. (2010). Yapay Zeka: İnsan-Bilgisayar Etkileşimi. (3. bsk.) Ankara: Seçkin.

Peltekoğlu, F Balta (2012). $\quad$ Halkla İlişkiler Nedir? 7. Baskı, İstanbul.

Tekeli, İ. (2011). Sosyal Sistem Yazıları. İstanbul: Tarih Vakfı Yurt Yayınları.

Türkeş Günay, U. (2013). Folklor ve Siber Çağ. Türk Dünyası İncelemeleri Dergisi, 13 (1) , ss.213221.

Zimmerman, M. E. (2011). Heidegger-Moderniteyle Hesaplaşmal Teknoloji, Politika, Sanat. İstanbul: Paradigma 